\title{
Effect of the acid suppressor omeprazole on the proliferation, migration, invasion and cell cycle of esophageal squamous cell carcinoma cells via the aryl hydrocarbon receptor pathway
}

\author{
YU BAI, PEIYAO ZHU, KUN ZHOU and SHU-GUANG ZHANG \\ Department of Thoracic Surgery, The First Hospital of China Medical University, Shenyang, Liaoning 110001, P.R. China
}

Received February 4, 2021; Accepted July 14, 2021

DOI: $10.3892 /$ etm.2021.10621

\begin{abstract}
Esophageal cancer is a malignant tumor type with one of the highest mortality rates worldwide. The aryl hydrocarbon receptor (AHR), which has been investigated in recent years, has been confirmed to be associated with the occurrence and development of esophageal cancer. AHR has a variety of different ligands, which regulate its activity following binding. The widely known acid inhibitor omeprazole (OME) also affects AHR and its downstream proteins (such as the cytochrome P450 family) by non-ligand binding; however, the mechanisms have remained to be fully elucidated. Therefore, the aim of the present study was to investigate the role of OME in esophageal squamous cell carcinoma (ESCC), whether the mechanism proceeds via the AHR pathway and how OME regulates AHR to affect the occurrence and development of esophageal carcinoma. The AHR-selective regulator OME was used to treat the ESCC cell lines TE1 and KYSE150. Western blot analysis was used to verify the effect of OME on AHR and proliferating cell nuclear antigen (PCNA) protein expression levels, while Cell Counting Kit (CCK)-8, wound-healing and Transwell assays were used to determine the proliferation, migration and invasion of the ESCCs, respectively, following treatment with OME. In addition, flow cytometry was used to investigate the cell cycle distribution of the ESCCs following incubation with OME. AHR was highly expressed in the ESCCs and following treatment with OME, the protein expression levels of AHR and PCNA were downregulated. The CCK-8 assay indicated that the proliferation of the ESCCs was also reduced following treatment with OME. Furthermore, flow cytometry revealed a notable block of the cells in $\mathrm{G}_{1} / \mathrm{G}_{0}$ phase, while the
\end{abstract}

Correspondence to: Professor Shu-Guang Zhang, Department of Thoracic Surgery, The First Hospital of China Medical University, 155 North Nanjing Street, Heping, Shenyang, Liaoning 110001, P.R. China

E-mail: shgzhang@cmu.edu.cn

Key words: omeprazole, esophageal squamous cell carcinoma, aryl hydrocarbon receptor, ligand, malignant tumor, proliferation, migration, invasion results of the wound-healing and Transwell assays respectively suggested that cell migration and invasion were reduced. In conclusion, OME inhibited the proliferation, migration and invasion of ESCC cells and blocked the cell cycle via the AHR pathway, which may provide a therapeutic effect on esophageal squamous cell cancer.

\section{Introduction}

According to the Global Cancer Observatory, 400,000 deaths from esophageal cancer occurred in 2012 and it ranks 6th among all cancer types worldwide (1-3). In addition, among the top 10 malignant tumor types in China, esophageal cancer ranks 4 th in males and 8th in females (4). The major pathological subtypes of esophageal cancer are squamous cell carcinoma, adenocarcinoma and small cell carcinoma, and squamous cell carcinoma is the major type in China, accounting for $>90 \%$ of cases, while adenocarcinoma is the major type in European countries and in both North and South America (5). The risk factors of the different pathological types of esophageal squamous cell carcinoma (ESCC) are also different and include sex, ethnicity, smoking, alcohol consumption, diet, nutritional status and hereditary factors (6).

The aryl hydrocarbon receptor (AHR) is in the basic helix-loop-helix/Per-ARNT-SIM (bHLH/PAS) subgroup in the bHLH transcription factor superfamily. The gene is $\sim 60 \mathrm{Kbp}$ long and has 22 exons. An unusual exon/intron junction sequence was detected in the 11th intron of the gene, which begins at the $5^{\prime}$ end of the GC region. The exon/intron organization of the mouse AhR nuclear translocator (mArnt) gene is different from the other members in the same bHLH/PAS family, as it does not contain a TATA box and has several transcriptional initiation sites (7). The promoter region of the mArnt gene is rich in GC and contains numerous hypothesized regulatory DNA sequences, such as two GC-boxes, a cyclic adenosine monophosphate response element, an E-box, an activator protein-1 locus and a CAAT-box. The AHR is the only member of the family, which is known to be activated by a ligand (8). The AHR is a ligand-activated transcription factor, located in the cytoplasm and combines with the heat shock protein (HSP)90, the AHR-interacting protein and the HSP90-interacting protein P23 (9). After the ligands are combined, the AHR is transported into the nucleus 
and dimerizes with the aryl receptor nuclear translocator. Subsequently, it combines with xenobiotic response elements to regulate and participate in the downstream signaling pathway $(9,10)$.

Omeprazole (OME; Fig. 1), a well-known acid suppressant, is used to inhibit the proton pump in gastric wall cells $\left(\mathrm{H}^{+} / \mathrm{K}^{+}\right.$ enzyme). In addition, animal experiments have demonstrated that OME had a protective effect on gastric mucosa damage, and was able to increase gastric mucosa blood flow due to an association with a variety of different factors, such as glycoproteins, nitric oxide and TNF- $\alpha$ (11). Furthermore, OME has an anti-Helicobacter pylori (H. pylori) effect (12). Due to its mode of action, OME is widely used in the treatment of peptic ulcers, reflux esophagitis, upper gastrointestinal hemorrhage, $H$. pylori infection, Zole-Aids syndrome and gastric ulcer caused by non-steroidal anti-inflammatory drugs (13). Following increases in AHR research, OME has also been indicated to be a selective regulator of AHR (14). Therefore, the present study aimed to investigate whether OME regulates the expression level of AHR in ESCC cells to affect the proliferation, cell cycle, migration and invasion, to provide a novel treatment for ESCC.

\section{Materials and methods}

Cell culture. The human ESCC cell lines TE1 and KYSE150 were purchased from the Chinese Academy of Sciences. The cells were cultured in RPMI-1640 medium (Beijing Solarbio Science \& Technology Co., Ltd.) containing 10\% FBS (Cellmax Nutrients B.V.) at $37^{\circ} \mathrm{C}$ in a humidified incubator with $5 \% \mathrm{CO}_{2}$.

Western blot analysis. OME was first dissolved in DMSO at a high concentration to produce a stock solution and then dissolved in the corresponding medium during later use (the concentration of DMSO in the final solution did not exceed $0.1 \%$ ). TE1 and KYSE150 cells were treated with 0, 100 and $300 \mu \mathrm{M}$ OME for $48 \mathrm{~h}$. The cells were then lysed with RIPA buffer (Beyotime Institute of Biotechnology) for $15 \mathrm{~min}$ and the protein was extracted. The concentration of total protein was measured using the bicinchoninic acid assay (Thermo Fisher Scientific, Inc.). Protein aliquots $(30 \mu \mathrm{g})$ were loaded with SDS buffer (Beyotime Institute of Biotechnology) and boiled at $99^{\circ} \mathrm{C}$ for $15 \mathrm{~min}$. Equal amounts of protein samples per lane were separated using SDS-PAGE on a $10 \%$ gel. Following electrophoresis, the cells were transferred to a PVDF membrane (EMD Millipore). Fast blocking solution (Beyotime Institute of Biotechnology) was used for blocking for $15 \mathrm{~min}$ at room temperature and the membrane was incubated with the following primary antibodies on a shaking table overnight at $4^{\circ} \mathrm{C}$ : Anti-GAPDH $(1: 1,000$; cat. no. ab181602; Abcam), anti-AHR (1:500; cat. no. ab182642; Abcam), anti-proliferating cell nuclear antigen (PCNA; 1:2,000; cat. no. 2586; Cell Signaling Technology, Inc.) and anti-MMP9 (1:1,000; cat. no. 3582; Cell Signaling Technology, Inc.). Subsequently, samples were incubated with the corresponding secondary antibodies: Goat anti-Rabbit secondary antibody (1:10,000; cat. no. 31460; Thermo Fisher Scientific, Inc.) and Goat anti-mouse secondary antibody (1:10,000; cat. no. 31430; Thermo Fisher Scientific, Inc.) for $2 \mathrm{~h}$ at room temperature,

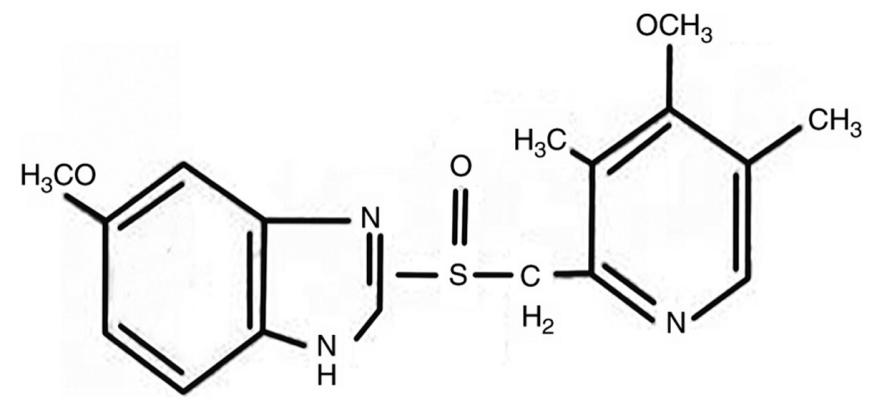

Figure 1. Molecular structure of omeprazole.

and blots were visualized using enhanced chemiluminescence (Beyotime Institute of Biotechnology) solution. The grayscale values of the resulting bands were measured using ImageJ software (version, 1.46r; National Institutes of Health). Each experiment was performed in triplicate.

Cell proliferation assay. The TE1 and KYSE150 cells were cultured, collected and then counted. Subsequently, the cells were seeded in a 96-well plate ( 2,000 cells/well; $200 \mu \mathrm{l} /$ well). After the cells had attached, they were treated with 0,100 and $300 \mu \mathrm{M}$ OME for at 24, 48, 72 or $96 \mathrm{~h}$. Cell Counting Kit-8 solution (MedChemExpress) was added for $2 \mathrm{~h}$ and cell proliferation was measured at $560 \mathrm{~nm}$ using a microplate reader (Thermo Fisher Scientific, Inc.). At the same time, the photomicrographs of the ESCCs were captured at 0, 24, 48, 72 and $96 \mathrm{~h}$ with an inverted microscope (magnification, x200). Each experiment was performed in triplicate.

Wound-healing assay. The TE1 and KYSE150 cells were cultured and seeded in a six-well plate. After the cells grew to $90 \%$ confluence $\left(\sim 1 \times 10^{6}\right.$ cells per well), they were scratched with a $200-\mu 1$ pipette tip and the serum-free medium was replaced with serum-free OME at 0,100 and $300 \mu \mathrm{M}$. Images of the wounds were captured at 0,24 and $48 \mathrm{~h}$ with an inverted microscope (magnification, $\mathrm{x} 50$ ). Wound areas were measured using ImageJ (version 1.46r; National Institutes of Health). The migration rate was then calculated as follows: (The difference of the wound area between 24, 48 and $0 \mathrm{~h}) /($ wound area at $0 \mathrm{~h}$ ). Each experiment was performed in triplicate.

Transwell assay. The TE1 and KYSE150 cells were collected and then seeded in a six-well plate. After the cells had attached, they were treated with OME at 0, 100 and $300 \mu \mathrm{M}$ for $48 \mathrm{~h}$. The cells were then collected and $\sim 5,000$ cells/well in $200 \mu \mathrm{l} /$ well were seeded into the upper chamber of a Transwell insert (Corning, Inc.) that had been pre-coated with Matrigel ${ }^{\mathrm{TM}}$ (1:8; BD Biosciences) for $30 \mathrm{~min}$ at $37^{\circ} \mathrm{C}$ for the invasion assay. RPMI-1640 medium containing 20\% FBS (500 $\mu \mathrm{l} /$ well) was added to the lower chamber. The cells were fixed with methanol for $10 \mathrm{~min}$ and stained with crystal violet for $20 \mathrm{~min}$ at room temperature. After $48 \mathrm{~h}$ of incubation, cells on the upper surface were scraped off and cells on the lower surface were viewed under a light microscope (Leica Microsystems; magnification, x100). Images were captured using ImageJ software. 
B

A

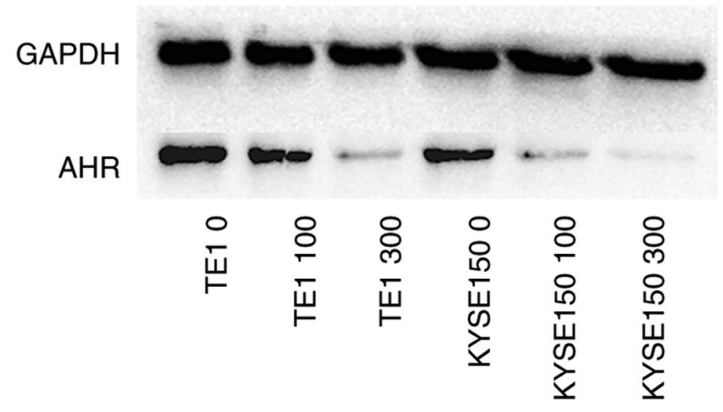

TE1 KYSE150

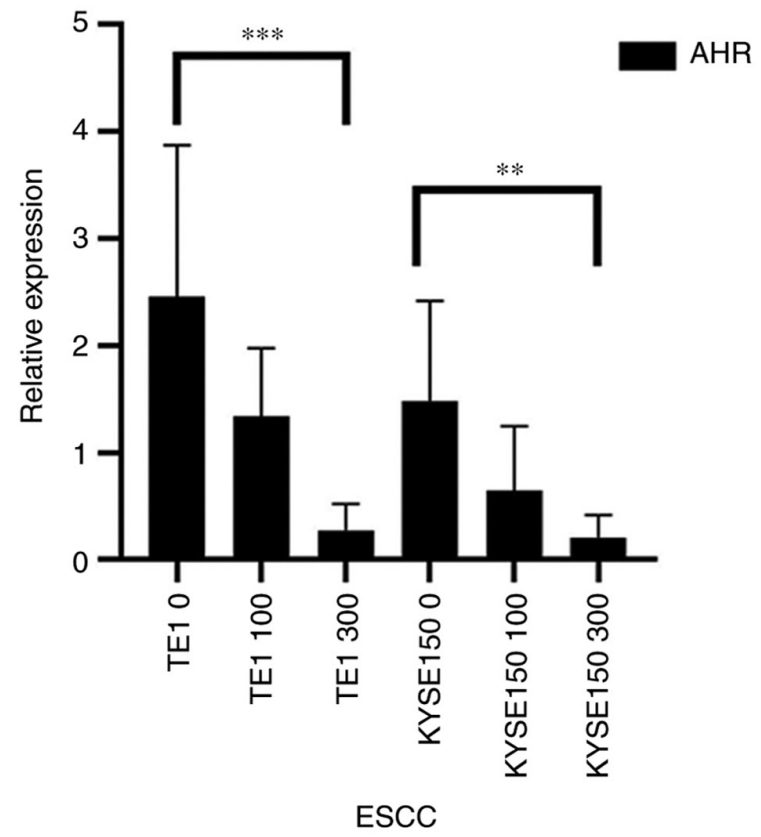

Figure 2. OME inhibits the protein expression levels of AHR. (A) The TE1 and KYSE150 cell lines were treated with 0 , 100 and $300 \mu$ M OME and the protein expression level of AHR was determined by western blot analysis. (B) The results were semi-quantitatively analyzed using gray-scale analysis. ${ }^{* * *} \mathrm{P}<0.001$ and ${ }^{* *} \mathrm{P}<0.01$. OME, omeprazole; AHR, aryl hydrocarbon receptor; ESCC, esophageal squamous cell carcinoma.

Cell cycle analysis. The TE1 and KYSE150 cells were collected and seeded in a six-well plate. Subsequently, the cells were treated with serum-free medium for $24 \mathrm{~h}$ and then with OME at 0,100 and $300 \mu \mathrm{M}$. After $48 \mathrm{~h}$, the cells were collected and fixed overnight in a flow tube (BD Biosciences) at $4^{\circ} \mathrm{C}$. A total of $490 \mu \mathrm{l}$ PBS was added to the cells and RNase A (Sigma Aldrich; Merck KGaA) was added. Following incubation in a $37^{\circ} \mathrm{C}$ water bath for $\sim 30 \mathrm{~min}$, the cells was stained with $10 \mu \mathrm{l}$ propidium iodide (PI; $50 \mu \mathrm{g} / \mathrm{ml}$, BD Biosciences) for $30 \mathrm{~min}$ on ice in the dark. The cell cycle was then measured using flow cytometry. The cell cycle distribution was detected by a BD LSRFortessa instrument (BD Biosciences) and the results were analyzed with ModFit software (version, LT 4.1; BD Biosciences).

Statistical analysis. All of the data were analyzed using SPSS software (version 20; IBM Corp.) and GraphPad Prism 5.04 (GraphPad Software, Inc.). One-way ANOVA and two-way ANOVA with Bonferroni's post-hoc test was used for comparing means of multiple samples. Experimental data are presented as the mean \pm standard deviation. The survival analysis was performed using the Kaplan-Meier method. $\mathrm{P}<0.05$ was considered to indicate a statistically significant difference.

\section{Results}

Inhibitory effect of $O M E$ on AHR expression. AHR, a ligand-activated transcription factor, has a variety of endogenous and exogenous ligands (15). In previous studies investigating other types of cancer, OME was indicated to regulate the expression level of AHR in a non-ligand manner (16). In addition, numerous studies have demonstrated the promoting effect of AHR on tumor development (17). In the present study, the inhibitory effect of OME on the protein expression level of AHR was determined using western blot analysis (Fig. 2A), which was also indicated to be significantly decreased with increasing doses of OME (Fig. 2B).

OME inhibits the proliferation of TE1 and KYSE150 cells. Numerous studies suggested that the ligands of AHR regulate the expression levels of AHR and thus the development of tumors $(18,19)$. In addition, OME was reported to be a selective regulator of AHR and to lower the expression level of AHR in previous research (16). Therefore, western blot analysis and cell proliferation assays were used in the present study to verify whether OME is able to reduce the proliferation of the ESCCs via AHR.

PCNA occurs in normal and tumor cells. The protein expression level of PCNA was decreased in a dose-dependent manner in the TE1 and KYSE150 cell lines treated with 0, 100 and $300 \mu \mathrm{M}$ OME for $48 \mathrm{~h}$ (Fig. 3A). As presented in Fig. 3B, the protein expression level of PCNA decreased with the increase in the OME concentration; however, the effect was small when the cells were treated with $100 \mu \mathrm{M}$ OME, which may be associated with the sensitivity of the different cell lines to the drug. The decrease in PCNA protein expression levels was significant when the cells were treated with $300 \mu \mathrm{M}$ OME.

In addition, to further confirm the effect of OME on the proliferation of the ESCCs, a CCK-8 assay was performed. It was revealed that the proliferation of the ESCCs was inhibited following OME treatment and the effect was significant and dose-dependent (Fig. 4A and B). Photomicrographs of the ESCCs in the different groups are presented in Fig. 5. 
B
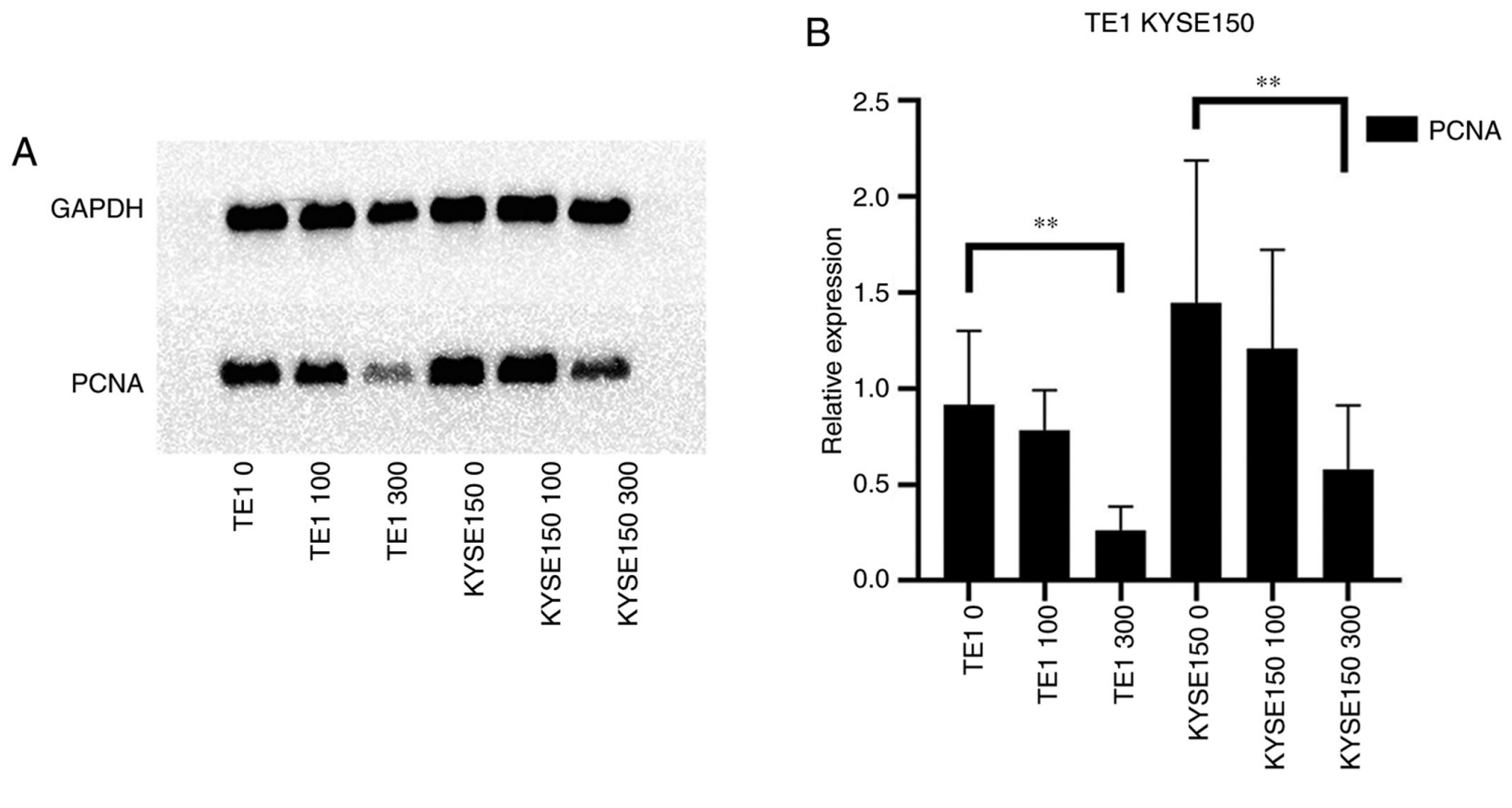

ESCC

Figure 3. OME decreases the protein expression levels of the proliferation-related gene PCNA. (A) The TE1 and KYSE150 cell lines were treated with 0, 100 and $300 \mu \mathrm{M}$ OME and the protein expression levels of PCNA were determined by western blot analysis. (B) The results were semi-quantitatively analyzed using gray-scale analysis ${ }^{* *} \mathrm{P}<0.01$. OME, omeprazole; PCNA, proliferating cell nuclear antigen; ESCC, esophageal squamous cell carcinoma.
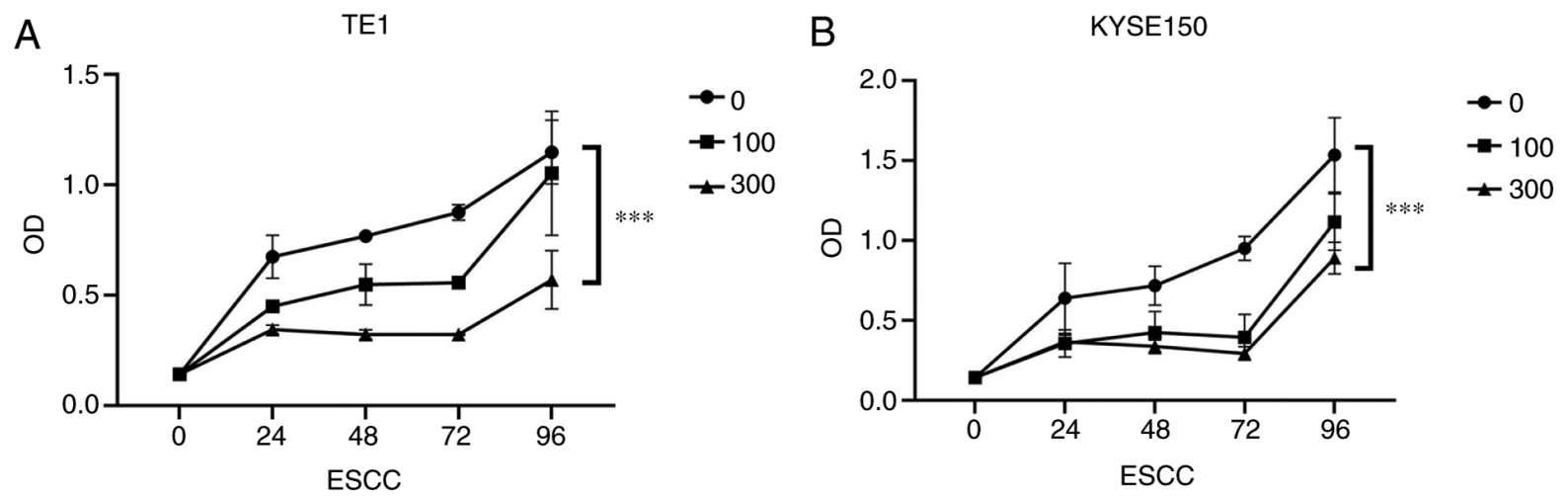

Figure 4. OME inhibits the proliferation of esophageal squamous cell carcinoma cells. Cell proliferation of the (A) TE1 and (B) KYSE150 cell lines following treatment with 0,100 and $300 \mu \mathrm{M}$ OME for 24, 48, 72 and $96 \mathrm{~h} .{ }^{* * *} \mathrm{P}<0.001$. OME, omeprazole; OD, optical density; ESCC, esophageal squamous cell carcinoma.

OME induces cell cycle arrest in $G_{1}$ phase. To identify how OME affects the cell cycle in the ESCCs, flow cytometry was performed and the number of cells in $\mathrm{G}_{1} / \mathrm{G}_{0}, \mathrm{~S}$ and $\mathrm{G}_{2}$ phase was measured. As presented in Fig. 6, after the TE1 cell line was treated with 0,100 and $300 \mu \mathrm{M}$ OME, the percentages of cells in $\mathrm{G}_{1} / \mathrm{G}_{0}$ phase were $32.74,38.29$ and $46.80 \%$, those in $S$ phase were $52.34,45.29$ and $42.10 \%$ and those in $G_{2} / M$ phase were $14.92,16.42$ and $11.10 \%$, respectively. Following treatment of the KYSE150 cell line with 0,100 and $300 \mu \mathrm{M}$ OME, the percentages of cells in $\mathrm{G}_{1} / \mathrm{G}_{0}$ phase were 48.23, 51.47 and $66.96 \%$, those in $\mathrm{S}$ phase were $42.14,39.15$ and $21.75 \%$, and those in $\mathrm{G}_{2} / \mathrm{M}$ phase were $9.63,9.38$ and $11.29 \%$, respectively. These data indicated that $\mathrm{OME}$ induced $\mathrm{G}_{1}$-phase arrest in the ESCCs in a dose-dependent manner, as increasing concentrations of omeprazole enhanced the proportion of cells that were blocked in $\mathrm{G}_{1} / \mathrm{G}_{0}$ phase.
OME reduces cell migration and invasion. Western blot analysis, wound healing and Transwell assays were used to confirm whether OME is able to affect cell migration and invasion.

Proteins of the MMP family are involved in extracellular matrix breakdown in normal physiological processes (such as embryonic development, reproduction and tissue remodeling) and in disease processes (such as arthritis and metastasis) (20). Thus, analyzing the protein expression levels of the MMP family may be used to investigate the invasive capacity of cells. The ESCCs were treated with different concentrations of OME and the protein expression levels of MMP9 were then analyzed (Fig. 7). Of note, OME reduced the protein expression level of MMP9, suggesting that OME may inhibit cell invasion.

The wound-healing assay indicated that the migratory ability of the TE1 and KYSE150 cell lines treated with OME 
A OME $(\mu \mathrm{M}) \quad 0 \mathrm{~h}$

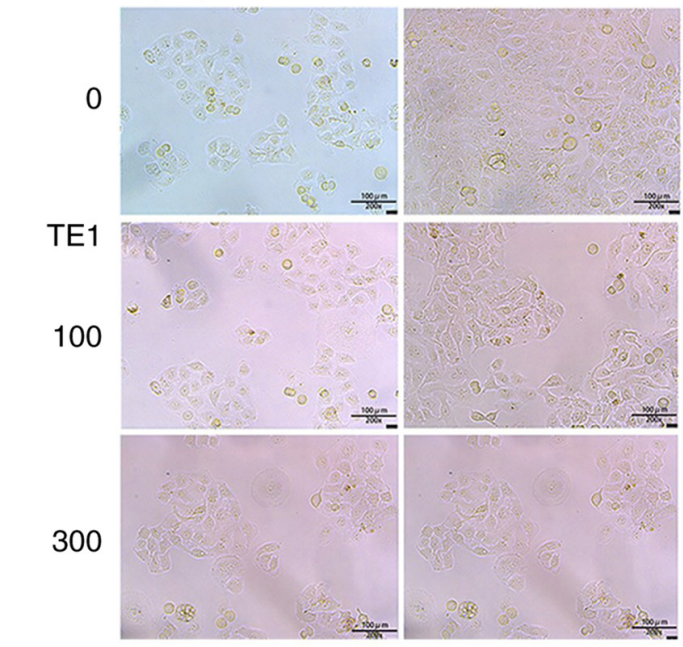

B OME $(\mu \mathrm{M}) \quad \mathrm{Oh}$
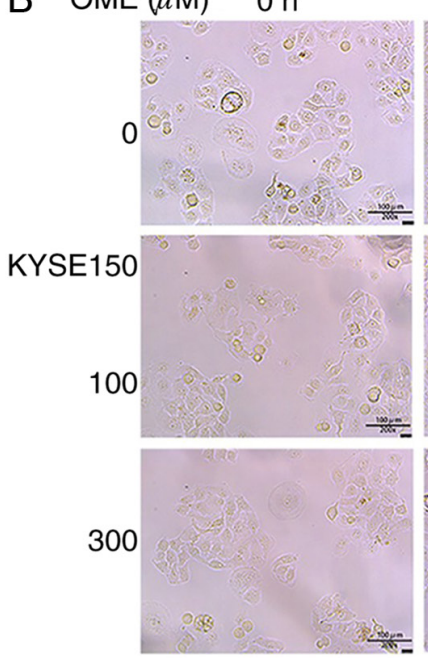

$24 \mathrm{~h}$

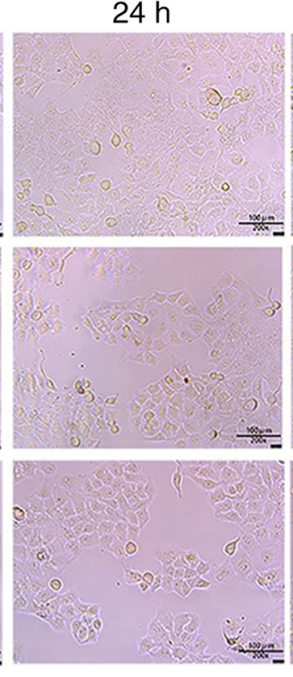

$48 \mathrm{~h}$

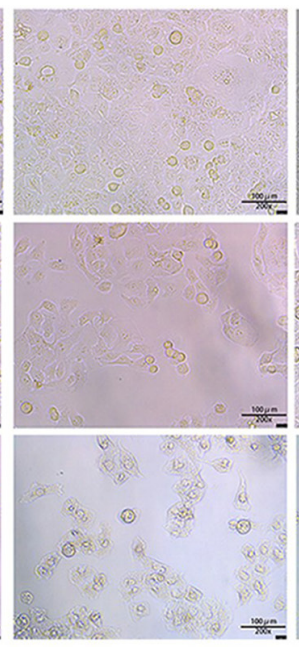

$48 \mathrm{~h}$
$72 \mathrm{~h}$
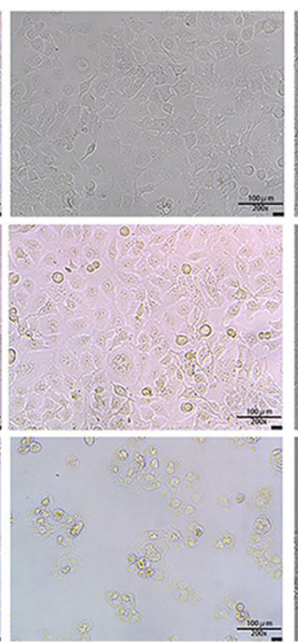

$72 \mathrm{~h}$
$96 \mathrm{~h}$

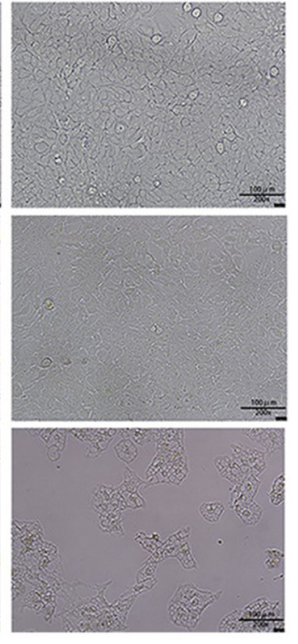

$96 \mathrm{~h}$
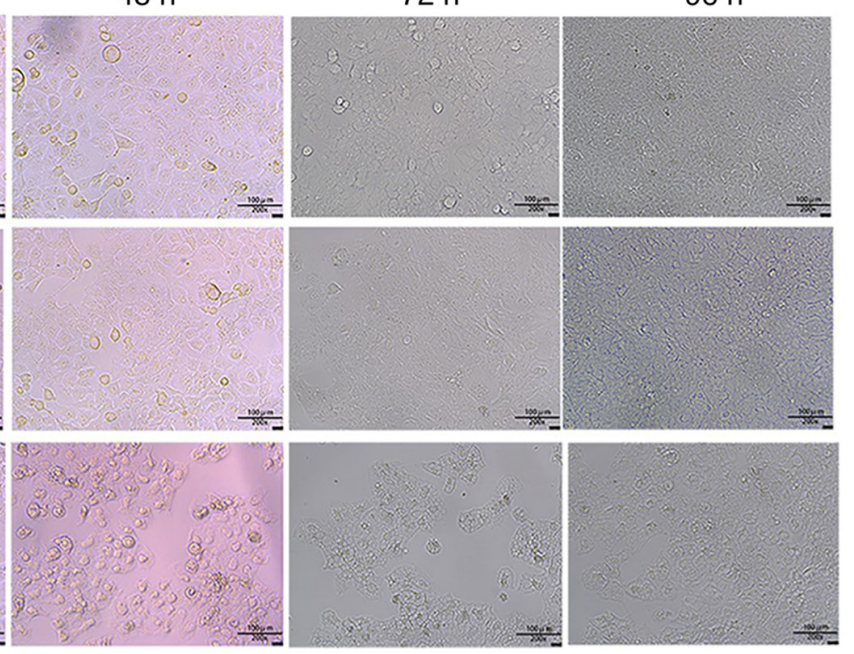

Figure 5. Photomicrographs of the (A) TE1 and (B) KYSE150 cells following treatment with 0, 100 and $300 \mu \mathrm{M}$ OME for 24, 48 and $72 \mathrm{~h}$. OME, omeprazole.

was reduced and the high concentration of OME inhibited migration to the greatest extent (Fig. 8). In addition, as expected, the results of the Transwell assay revealed that the invasive ability of the TE1 and KYSE150 cells treated with OME was also reduced and this effect was observed to be dose-dependent (Fig. 9).

\section{Discussion}

Esophageal cancer is one of the most common types of cancer in the Western world, with high aggressiveness and a low 5-year survival rate. Despite advances in diagnosis and treatment, the overall 5-year survival rate for patients with esophageal cancer is only $15-20 \%$ in the US (21). There are two major subtypes of esophageal cancer: Squamous cell carcinoma and adenocarcinoma, and both account for $>95 \%$ of cases of esophageal cancer. Clinical studies have indicated that the combination of OME and aspirin reduced the mortality rate in patients with esophageal adenocarcinoma (22). Therefore, the present study focused on ESCC and OME.

AHR, as a ligand-activated transcription factor, has been investigated in numerous types of tumor, such as colorectal (23), breast (24,25), lung (26-28), stomach (29), skin (30), prostate (31) and pancreatic cancers $(32,33)$. High protein expression levels were confirmed in the present study and promoted the process of tumor development. AHR has a variety of endogenous and exogenous ligands, and in previous studies, OME, a widely known acid inhibitor, has also been determined to be a selective regulator of AHR. OME is a proton pump inhibitor, which is widely used in the treatment of various diseases, including digestive tract ulcers and reflux esophagitis. In addition, OME was indicated to regulate the expression level of AHR in a non-ligand manner, thereby affecting the occurrence and development of tumors $(14,16,29)$. However, the underlying mechanism has remained elusive, and to the best of our knowledge, no previous studies have investigated the effect of the interaction between OME and AHR on tumorigenesis and progression of ESCC.

From the results of the present study, several conclusions may be drawn. First, western blot analysis revealed that the TE1 and KYSE150 cell lines treated with 0, 100 and $300 \mu \mathrm{M}$ OME for $48 \mathrm{~h}$ exhibited decreased AHR protein expression levels and this effect was dose-dependent. Combined with the results of previous studies by our group $(34,35)$, it may be preliminarily suggested that OME affects the proliferation, 

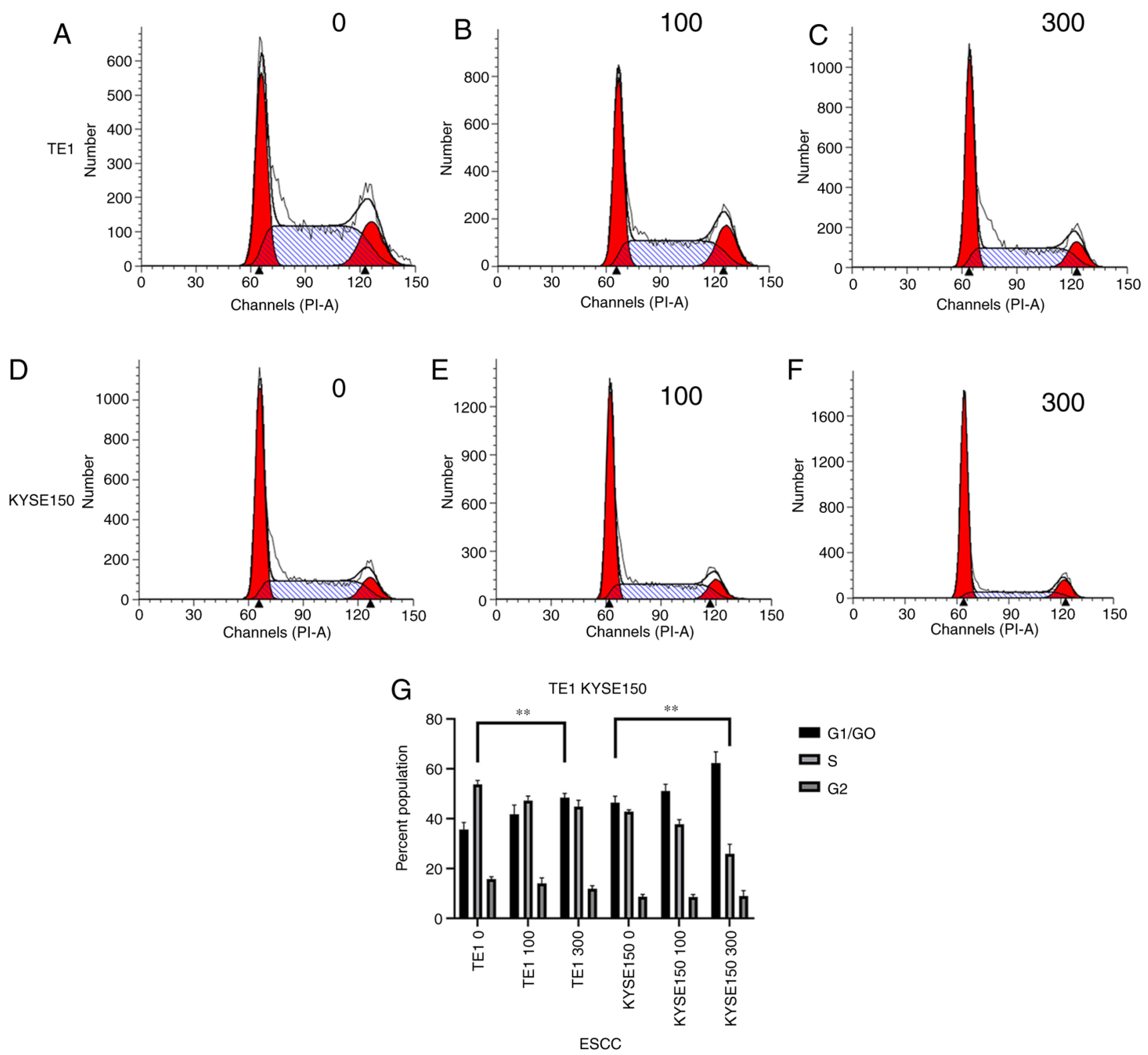

Figure 6. OME induces $\mathrm{G}_{1}$ phase arrest in esophageal squamous cell carcinoma cells. Cell cycle distribution of the TE1 cell line treated with (A) 0 , (B) 100 and (C) $300 \mu \mathrm{M}$ OME for $48 \mathrm{~h}$. Cell cycle distribution of the KYSE150 cell line treated with (D) 0 , (E) 100 and (F) $300 \mu \mathrm{M}$ OME. (G) Proportion of cells in $\mathrm{G}_{1} / \mathrm{G}_{0}, \mathrm{~S}$ and $\mathrm{G}_{2} / \mathrm{M}$ phases according to quantitative analysis of the TE1 and KYSE150 cell lines (G1/G0 phase; * $\left.\mathrm{P}<0.01\right)$. OME, omeprazole; ESCC, esophageal squamous cell carcinoma.

migration, invasion and cell cycle of ESCCs. Furthermore, the protein expression level of PCNA was also decreased when the TE1 and KYSE150 cell lines were treated with 0,100 and $300 \mu \mathrm{M}$ OME. In addition, the results of the cell proliferation assay suggested that the proliferation of the cells treated with OME was significantly inhibited and the inhibitory effect was more notable when the concentration of OME was increased. Cell cycle analysis then revealed that TE1 and KYSE150 cells treated with 0,100 and $300 \mu \mathrm{M}$ OME for $48 \mathrm{~h}$ exhibited gradual increases in the $\mathrm{G}_{1} / \mathrm{G}_{0}$ phase population and decreases in the percentages of cells in the $\mathrm{S}$ phases. This suggested that $\mathrm{OME}$ induced $\mathrm{G}_{1} / \mathrm{G}_{0}$ phase arrest in ESCCs. Furthermore, from the wound-healing and Transwell assays, it was concluded that OME inhibited the migration and invasion of the ESCCs, which was also associated with the concentration of OME. As a limitation, the present study did not determine the underlying mechanism by which OME affected the expression level of AHR. However, an apoptosis experiment was performed, which had an invalid result. Furthermore, there are numerous agonists and inhibitors of AHR, but no further research was performed as they lie beyond the scope of the present study. However, the agonists and inhibitors of AHR may act as the potential focus of future investigations. Although the effect of OME on the growth of tumors has not been investigated in vivo, OME, via the AHR pathway, was demonstrated to be able to inhibit the proliferation, migration and invasion of ESCC cells and cause cell cycle arrest at the $\mathrm{G}_{1} / \mathrm{G}_{0}$ phase, thus exerting inhibitory effects on ESCC.

In summary, OME selectively regulated and inhibited AHR expression, thereby exerting inhibitory effects on tumor cell proliferation, migration and invasion, along with the induction of $\mathrm{G}_{1} / \mathrm{G}_{0}$-phase arrest. The mechanism by which 

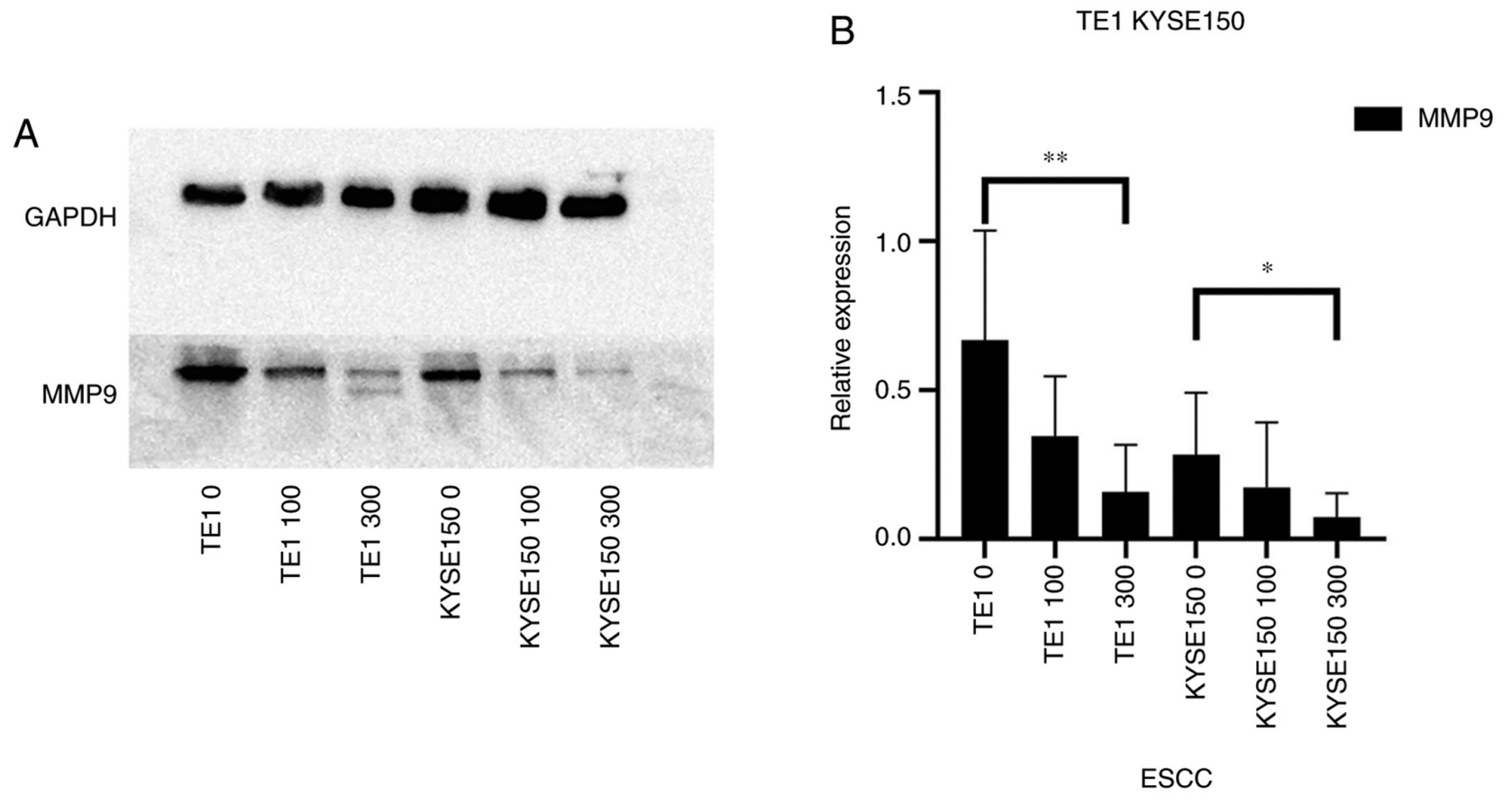

Figure 7. OME inhibits the protein expression of MMP9. (A) The protein expression of MMP9 in the TE1 and KYSE150 cell lines treated with 0, 100 and $300 \mu \mathrm{M}$ OME were determined by western blot analysis. (B) The results were quantitatively analyzed using gray-scale analysis. ${ }^{* *} \mathrm{P}<0.01$ and ${ }^{*} \mathrm{P}<0.05$. OME, omeprazole; ESCC, esophageal squamous cell carcinoma.
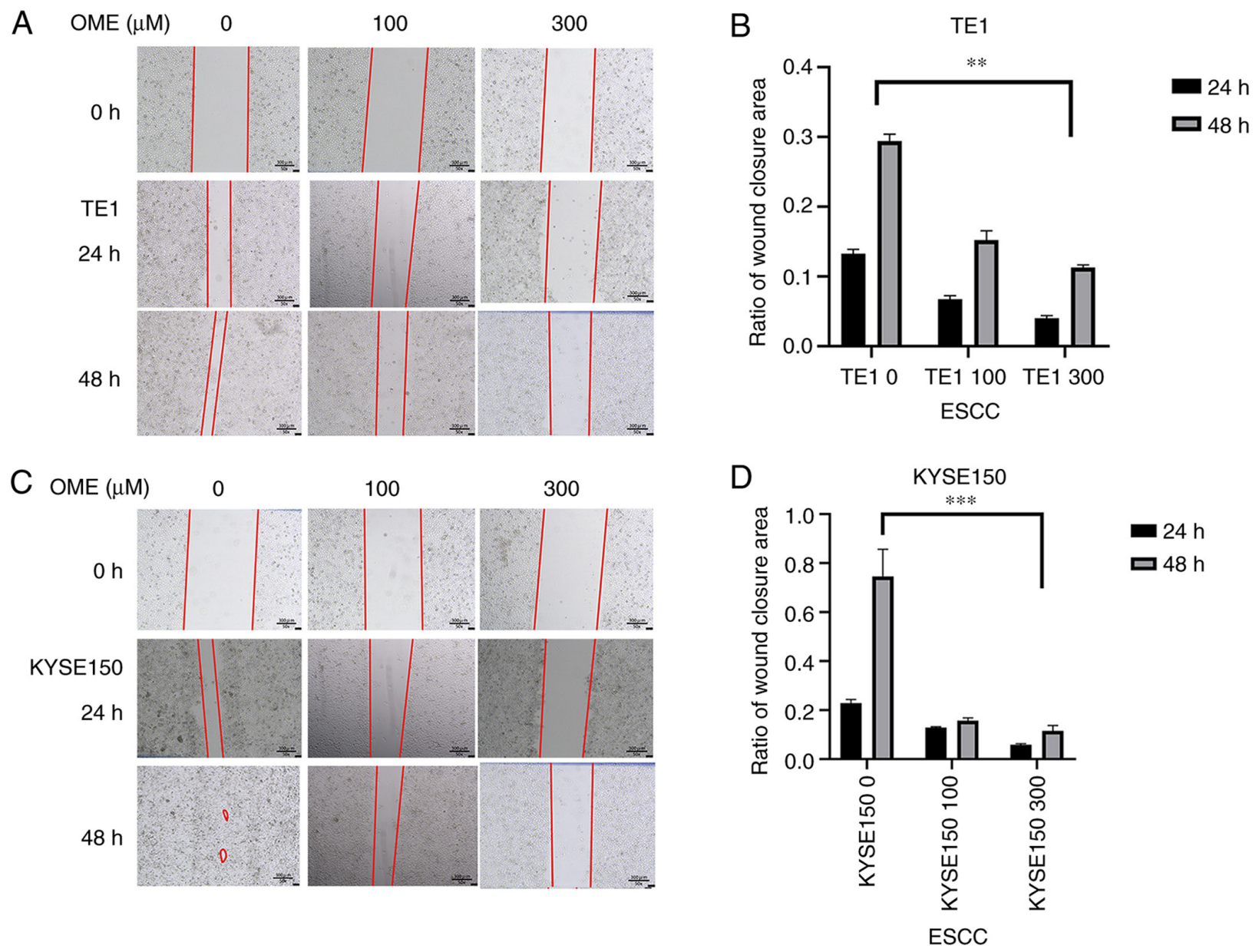

Figure 8. OME reduces the migratory ability of the esophageal squamous cell carcinoma cells. (A and C) Representative images from the wound healing assay of (A) TE1 and (C) KYSE150 cells treated with 0, 100 and $300 \mu \mathrm{M}$ OME for 24 or $48 \mathrm{~h}$ (magnification, x50; scale bar, $300 \mu \mathrm{m}$ ). (B and D) The results were quantitatively analyzed and the ratio of wound closure area for (B) TE1 and (D) KYSE150 cells is presented. ${ }^{* *} \mathrm{P}<0.01$ and ${ }^{* * *} \mathrm{P}<0.001$. OME, omeprazole; ESCC, esophageal squamous cell carcinoma. 


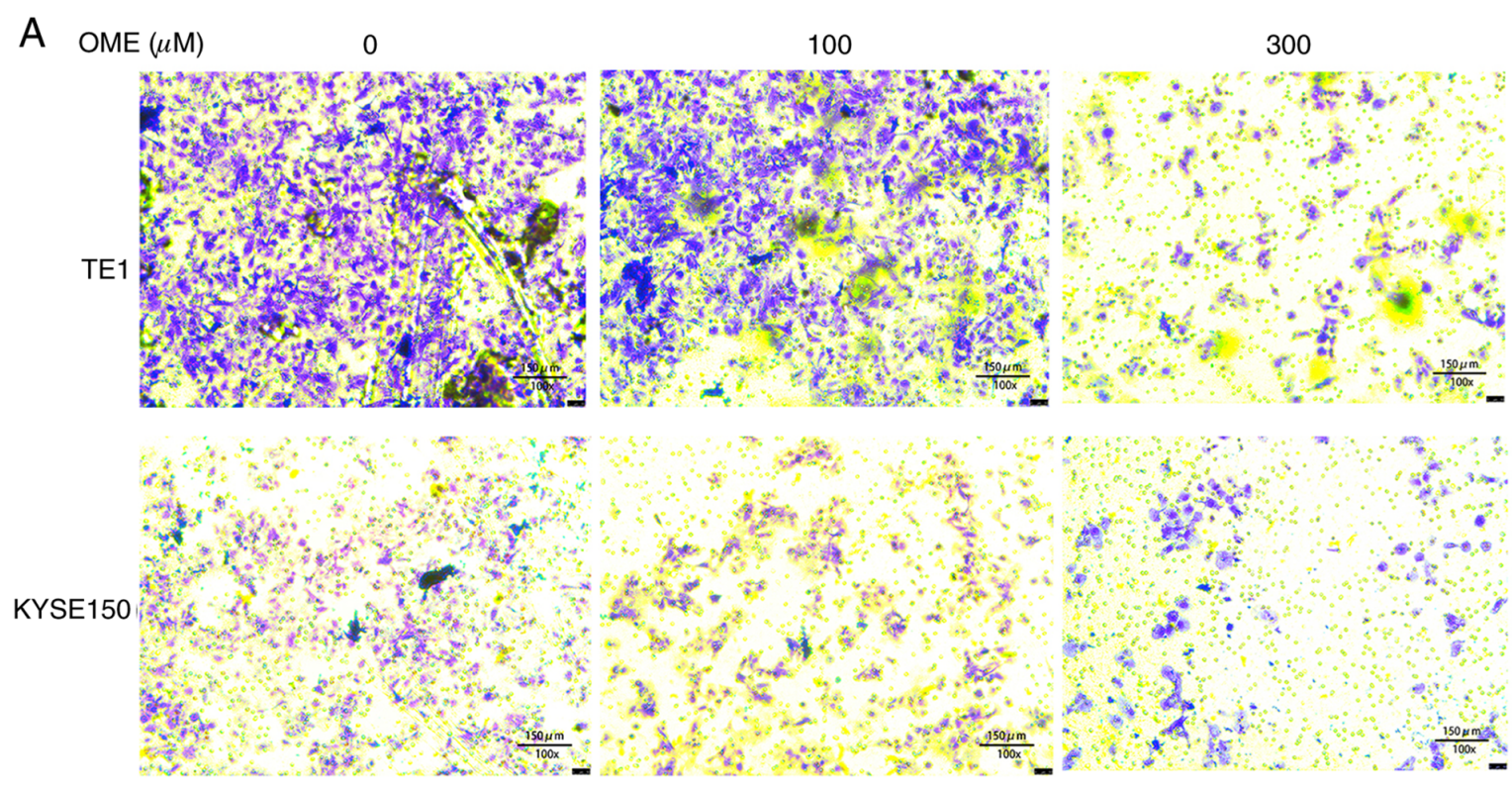

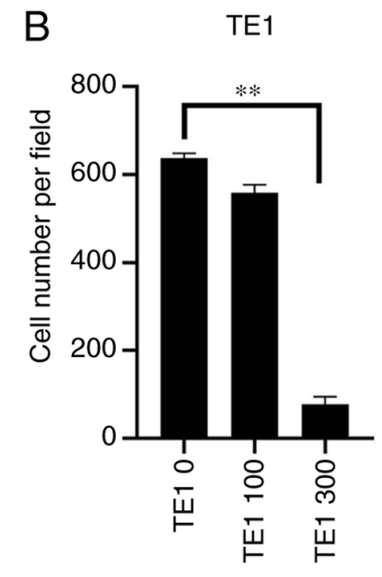

ESCC

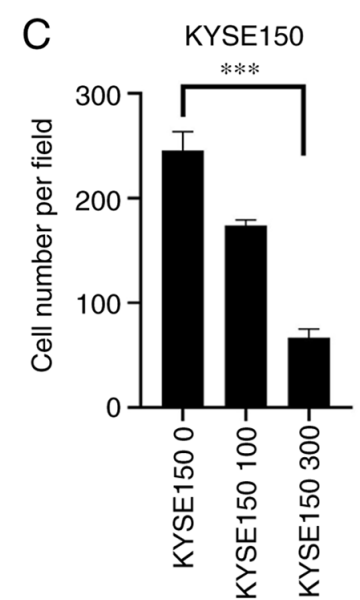

ESCC

Figure 9. OME reduces the invasive capacity of ESCC cells. (A) The invasive ability of the TE1 and KYSE150 cell lines treated with 0,100 and $300 \mu \mathrm{M}$ OME was assessed in a Transwell assay and representative images of membranes with stained invaded cells are provided (magnification, $\mathrm{x} 100$; scale bar, $150 \mu \mathrm{m}$ ). (B and C) Invasion of (B) TE1 and (C) KYSE150 cells was quantitatively analyzed. ${ }^{* *} \mathrm{P}<0.01$ and ${ }^{* * *} \mathrm{P}<0.001$. OME, omeprazole; ESCC, esophageal squamous cell carcinoma.

OME regulated AHR was not determined in the present study; however, the results proved the effect of OME on ESCC via the AHR pathway, which may be a potential treatment for ESCC in the future.

\section{Acknowledgements}

The authors gratefully acknowledge the contribution of $\mathrm{Dr}$ Rui-Qun Qi (Department of Dermatology, The First Hospital of China Medical University, Shenyang, China) for providing all aforementioned instruments.

\section{Funding}

The present research was supported by grants from the Natural Science Foundation of China (grant no. 81201890) and the Research Foundation of the Education Bureau of Liaoning Province, China (grant no. LK201614).

\section{Availability of data and materials}

The datasets used and/or analyzed during the current study are available from the corresponding author on reasonable request.

\section{Authors' contributions}

SGZ and YB designed the study. YB, PZ and KZ performed the research and recorded and analyzed the results. SGZ and YB wrote the manuscript. PZ and KZ carefully edited the manuscript and provided guidance and advice. BY and SGZ confirm the authenticity of all the raw data. All authors read and approved the final manuscript.

\section{Ethics approval and consent to participate}

Not applicable. 


\section{Patient consent for publication}

Not applicable.

\section{Competing interests}

The authors declare that they have no competing interests.

\section{References}

1. Ilic M, Kocic S, Radovanovic D, Macuzic IZ and Ilic I: Trend in esophageal cancer mortality in Serbia, 1991-2015 (a populationbased study): An age-period-cohort analysis and a joinpoint regression analysis. J BUON 24: 1233-1239, 2019.

2. Ferlay J, Soerjomataram I, Dikshit R, Eser S, Mathers C, Rebelo M, Parkin DM, Forman D and Bray F: Cancer incidence and mortality worldwide: Sources, methods and major patterns in GLOBOCAN 2012. Int J Cancer 136: E359-E386, 2015.

3. Malhotra G, Yanala U, Ravipati A, Follet M, Vijayakumar M and Are C: Global trends in esophageal cancer. J Surg Oncol 115: 564-579, 2017.

4. Lin Y, Totsuka Y, He Y, Kikuchi S, Qiao Y, Ueda J, Wei W, Inoue $\mathrm{M}$ and Tanaka $\mathrm{H}$ : Epidemiology of esophageal cancer in Japan and China. J Epidemiol 23: 233-242, 2013.

5. Smyth E, Lagergren J, Fitzgerald R, Lordick F, Shah M, Lagergren P and Cunningham D: Oesophageal cancer. Nat Rev Dis primers 3: 17048, 2017

6. Arnal MJ, Arenas ÁA and Arbeloa ÁL: Esophageal cancer: Risk factors, screening and endoscopic treatment in Western and Eastern countries. World J Gastroenterol 21: 7933-7943, 2015.

7. Schulte K, Green E, Wilz A, Platten M and Daumke O: Structural basis for aryl hydrocarbon receptor-mediated gene activation. Structure 25: 1025-1033, 2017.

8. Wang F, Gao J, Mimura J, Kobayashi A, Sogawa K and Fujii-Kuriyama Y: Structure and expression of the mouse AhR nuclear translocator (mArnt) gene. J Biol Chem 273: 24867-24873, 1998.

9. Nebert D: Aryl hydrocarbon receptor (AHR): 'Pioneer member' of the basic-helix/loop/helix per-Arnt-sim (bHLH/PAS) family of 'sensors' of foreign and endogenous signals. Prog Lipid Res 67: 38-57, 2017.

10. Shiizaki K, Ohsako S, Kawanishi M and Yagi T: Omeprazole alleviates benzo[a]pyrene cytotoxicity by inhibition of CYP1A1 activity in human and mouse hepatoma cells. Basic Clin Pharmacol Toxicol 103: 468-475, 2008

11. Gao W, Li HY, Wang LX, Hao LJ, Gao JL, Zheng RJ, Cai CJ and Si YL: Protective effect of omeprazole on gastric mucosal of cirrhotic portal hypertension rats. Asian Pac J Trop Med 7: 402-406, 2014

12. Weil J, Bell GD, Powell K, Morden A, Harrison G, Gant PW, Jones PH and Trowell JE: Omeprazole and helicobacter pylori: Temporary suppression rather than true eradication. Aliment Pharmacol Ther 5: 309-313, 1991.

13. Blum R: Lansoprazole and omeprazole in the treatment of acid peptic disorders. Am J Health Syst Pharm 53: 1401-1415, 1996.

14. Jin UH, Lee SO and Safe S: Aryl hydrocarbon receptor (AHR)-active pharmaceuticals are selective AHR modulators in MDA-MB-468 and BT474 breast cancer cells. J Pharmacol Exp Ther 343: 333-341, 2012.

15. Nguyen LP and Bradfield CA: The search for endogenous activators of the aryl hydrocarbon receptor. Chem Res Toxicol 21: 102-116, 2008

16. Jin UH, Kim SB and Safe S: Omeprazole inhibits pancreatic cancer cell invasion through a nongenomic aryl hydrocarbon receptor pathway. Chem Res Toxicol 28: 907-918, 2015.

17. Murray IA, Patterson AD and Perdew GH: Aryl hydrocarbon receptor ligands in cancer: Friend and foe. Nat Rev Cancer 14 801-814, 2014.
18. Patrizi B and Siciliani de Cumis M: TCDD toxicity mediated by epigenetic mechanisms. Int J Mol Sci 19: 4101, 2018.

19. Opitz C, Litzenburger U, Sahm F, Ott M, Tritschler I, Trump S, Schumacher T, Jestaedt L, Schrenk D, Weller M, et al: An endogenous tumour-promoting ligand of the human aryl hydrocarbon receptor. Nature 478: 197-203, 2011.

20. Huang H: Matrix metalloproteinase-9 (MMP-9) as a cancer biomarker and MMP-9 biosensors: Recent advances. Sensors (Basel) 18: 3249, 2018

21. Pennathur A, Gibson MK, Jobe BA and Luketich JD: Oesophageal carcinoma. Lancet 381: 400-412, 2013.

22. Jankowski JAZ, de Caestecker J, Love SB, Reilly G, Watson P, Sanders S, Ang Y, Morris D, Bhandari P, Brooks C, et al: Esomeprazole and aspirin in Barrett's oesophagus (AspECT): A randomised factorial trial. Lancet 392: 400-408, 2018.

23. Shiizaki K, Kido K and Mizuta Y: Insight into the relationship between aryl-hydrocarbon receptor and $\beta$-catenin in human colon cancer cells. PLoS One 14: e0224613, 2019.

24. Tomblin JK, Arthur S, Primerano DA, Chaudhry AR, Fan J, Denvir J and Salisbury TB: Aryl hydrocarbon receptor (AHR) regulation of L-type amino acid transporter 1 (LAT-1) expression in MCF-7 and MDA-MB-231 breast cancer cells. Biochem Pharmacol 106: 94-103, 2016.

25. Donovan M, Selmin O and Romagnolo D: Aryl hydrocarbon receptor diet and breast cancer risk. Yale J Biol Med 91: 105-127, 2018.

26. Terashima J, Jimma Y, Jimma K, Hakata S, Yachi M, Habano W and Ozawa S: The regulation mechanism of AhR activated by benzo[a]pyrene for CYP expression are different between 2D and 3D culture of human lung cancer cells. Drug Metab Pharmacokinet 33: 211-214, 2018.

27. Gao H, Ye G, Lin Y, Chi Y and Dong S: Benzo[a]pyrene at human blood equivalent level induces human lung epithelial cell invasion and migration via aryl hydrocarbon receptor signaling. J Appl Toxicol 40: 1087-1098, 2020.

28. Dong S, Zhu P and Zhang S: Expression of collagen type 1 alpha 1 indicates lymph node metastasis and poor outcomes in squamous cell carcinomas of the lung. PeerJ 8: e10089, 2020.

29. Yoshinari K, Ueda R, Kusano K, Yoshimura T, Nagata K and Yamazoe Y: Omeprazole transactivates human CYP1A1 and CYP1A2 expression through the common regulatory region containing multiple xenobiotic-responsive elements. Biochem Pharmacol 76: 139-145, 2008

30. Vogeley C, Esser C, Tüting T, Krutmann J and HaarmannStemmann T: Role of the aryl hydrocarbon receptor in environmentally induced skin aging and skin carcinogenesis. Int J Mol Sci 20: 6005, 2019.

31. Chen Z, Cai A, Zheng H, Huang H, Sun R, Cui X, Ye W, Yao Q, Chen $\mathrm{R}$ and Kou L: Carbidopa suppresses prostate cancer via aryl hydrocarbon receptor-mediated ubiquitination and degradation of androgen receptor. Oncogenesis 9: 49, 2020.

32. Wang L, Tang W, Yang S, He P, Wang J, Gaedcke J, Ströbel P, Azizian A, Ried T, Gaida MM, et al: NO /RUNX3/kynurenine metabolic signaling enhances disease aggressiveness in pancreatic cancer. Int J Cancer 146: 3160-3169, 2020.

33. Masoudi S, Nemati AH, Fazli HR, Beygi S, Moradzadeh M, Pourshams A and Mohamadkhani A: An increased level of aryl hydrocarbon receptor in patients with pancreatic cancer. Middle East J Dig Dis 11: 38-44, 2019.

34. Zhu P, Yu H, Zhou K, Bai Y, Qi R and Zhang S: 3,3'-Diindolylmethane modulates aryl hydrocarbon receptor of esophageal squamous cell carcinoma to reverse epithelial-mesenchymal transition through repressing RhoA/ROCK1-mediated COX2/PGE2 pathway. J Exp Clin Cancer Res 39: 113, 2020.

35. Zhu P, Zhou K, Lu S, Bai Y, Qi R and Zhang S: Modulation of aryl hydrocarbon receptor inhibits esophageal squamous cell carcinoma progression by repressing COX2/PGE2/STAT3 axis. J Cell Commun Signal 14: 175-192, 2020.

(i) $($ This work is licensed under a Creative Commons Attribution-NonCommercial-NoDerivatives 4.0 International (CC BY-NC-ND 4.0) License. 